
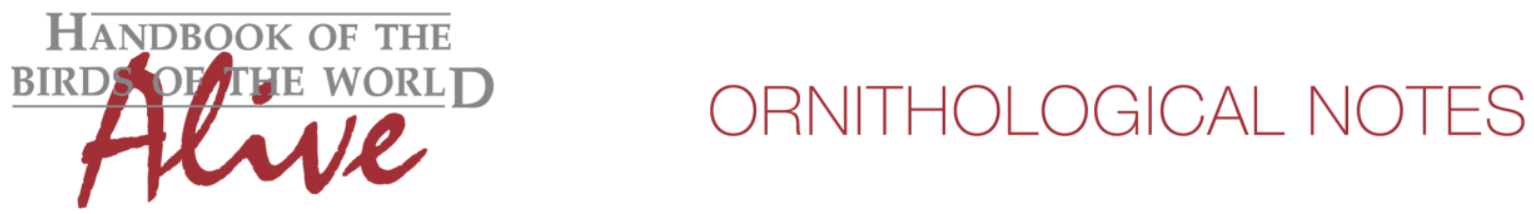

\title{
Notes on the vocalizations of Dull-mantled Antbird (Myrmeciza laemosticta)
}

\section{Peter Boesman}

In the following we briefly analyze and compare voice of the two races of Dull-mantled Antbird (Myrmeciza laemosticta) in order to quantify the extent of any vocal differences as a support for taxonomic review. We have made use of sound recordings available on-line from Xeno Canto (XC).

Voice of the two races palliata and laemosticta has already been analyzed previously (Chaves et al. 2010). It was subsequently also extensively discussed in http://www.museum.Isu.edu/ Remsen/SACCprop475.html

The overall conclusion being that palliata is (far) more different vocally from laemosticta, than palliata from Esmeraldas Antbird M. nigricauda. An additional quick comparison of palliata vs nigricauda was performed, after which it was agreed that vocal difference is here also 'large enough' using with some flexibility standards for allopatric populations in antbirds (Isler et al. 1998).

In the following we evaluate the same data using however the criteria proposed by Tobias et al. (2010). Table 2 from the Chaves paper allows to calculate some effect sizes:

palliata vs. laemosticta

duration (s)

pace $(\mathrm{n} / \mathrm{s})$

interval length (s)
$2.46 \pm 0.32$ vs $1.67 \pm 0.16$-> effect size 3.12 -> score 2

$3.10 \pm 0.28$ vs. $5.03 \pm 0.45$-> effect size 5.15 -> score 3

$162.68 \pm 27.32$ vs. $98.24 \pm 38.46$-> effect size 1.93 -> score 1

Besides the parameters measured, more parameters which quantify the important vocal difference could be defined, such as e.g. difference in max. freq. of the two last notes, with palliata/nigrescens ending with a much higher-pitched last note, which would also lead to a score of 2 or 3 (when making abstraction of 'incomplete songs')(Fig. 1).

In any case, it is clear that both taxa differ significantly in loudsong, leading to a total score of 5 or 6. 

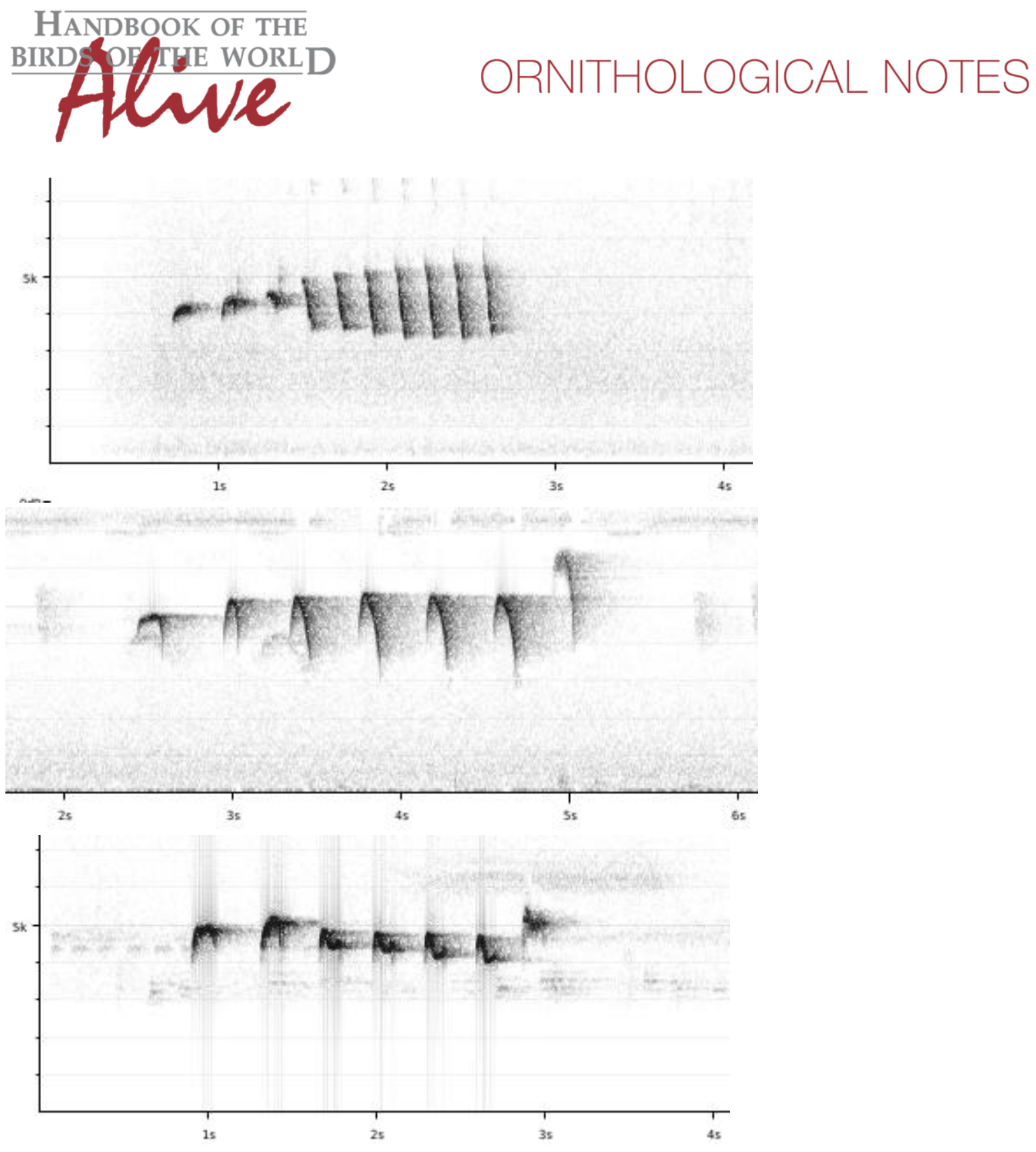

Figure 1: top to bottom: typical loudsong of M.I.laemosticta (Panama), M.I.palliata (N Colombia) and M. nigricauda (NW Ecuador)

In the same way we can quantify vocal differences between palliata and nigricauda:

palliata vs. nigricauda

duration (s)

pace $(\mathrm{n} / \mathrm{s})$

interval length $(s)$

peak frequency $(\mathrm{Hz})$
$2.46 \pm 0.32$ vs. $2.13 \pm 0.18$-> effect size 1.27 -> score 1

$3.10 \pm 0.28$ vs. $3.16 \pm 0.35$-> effect size 0 -> score 0

$162.68 \pm 27.32$ vs. $187.67 \pm 56.58$-> effect size 0.5 -> score 1

$4609 \pm 266$ vs. $5178.3 \pm 327$-> effect size 2.91 -> score 2

The data were taken from a rather small number of recordings $(n=10)$. Given that most differences are very small, they would have to be confirmed by measuring a larger number of samples (which are becoming available gradually). 

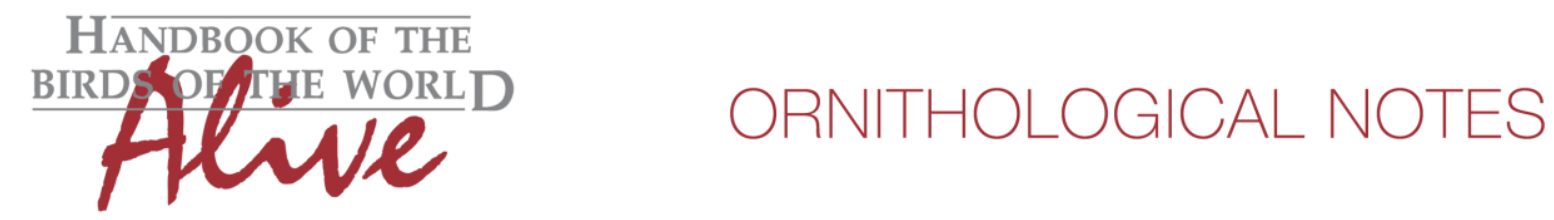

Again, besides the parameters measured, a few more parameters could be defined which quantify the subtle differences between both races. E.g. palliata notes gradually increase slightly in pitch, nigricauda notes decrease in pitch at some point. One could define the parameter 'max. freq. first note minus max. freq. third last note'.

Making abstraction of 'incomplete songs' this gives the following measurements:

palliata freq. change $\mathrm{c}+400 \mathrm{~Hz}$ to $+900 \mathrm{~Hz}$

nigricauda freq. change $\mathrm{c}-50 \mathrm{OHz}$ to $\mathrm{OHz}$

This leads to a score of about 2-3. This is however also a frequency-related parameter (although more related to freq. range rather than peak freq.).

There is also a difference in note shape, with palliata having mostly round overslurred notes, and nigricauda having a more irregular shape, especially towards the end.

From all data together, it would seem that vocal differences between M.I. palliata and $M$. nigricauda are indeed less striking but nevertheless reach a total score of about 3-4.

This note was finalized on 11th May 2015, using sound recordings available on-line at that moment. We would like to thank in particular the sound recordists who placed their recordings for this species on XC: Ken Allaire, Peter Boesman, David Bradley, Diego Calderon, Juan Chaves, Andres Cuervo, Thomas Donegan, Ottavio Janni, Jose Gustavo Leon, Hans Matheve, Alexandre Renaudier, Andrew Spencer and Tom Stevens.

\section{References}

Chaves, J. C., A. M. Cuervo, M. J. Miller, \& C. D. Cadena (2010). Revising species limits in a group of Myrmeciza antbirds reveals a cryptic species within M. laemosticta (Thamnophilidae). The Condor 112: 718-730.

Isler, M. L., P. R. Isler, and B. M. Whitney (1998). Use of vocalizations to establish species limits in antbirds (Passeriformes; Thamnophilidae). Auk 115:577-590.

Tobias, J.A., Seddon, N., Spottiswoode, C.N., Pilgrim, J.D., Fishpool, L.D.C. \& Collar, N.J. (2010). Quantitative criteria for species delimitation. Ibis 152(4): 724-746.

\section{Recommended citation}

Boesman, P. (2016). Notes on the vocalizations of Dull-mantled Antbird (Myrmeciza laemosticta). HBW Alive Ornithological Note 62. In: Handbook of the Birds of the World Alive. Lynx Edicions, Barcelona. (retrieved from http://www.hbw.com/node/931945 on 14 May 2016). 